\title{
Thickness dependence of properties of excimer laser crystallized nano-polycrystalline silicon
}

\author{
A. A. D. T. Adikaari ${ }^{\mathrm{a})}$ and S. R. P. Silva \\ Nano-Electronics Centre, Advanced Technology Institute, School of Electronics and Physical Sciences, \\ University of Surrey, Guildford, GU2 7XH, United Kingdom
}

(Received 27 August 2004; accepted 7 March 2005; published online 24 May 2005)

\begin{abstract}
Excimer laser crystallization is used to produce layered nanocrystalline silicon from hydrogenated amorphous silicon, using a partial melting process. Three types of hydrogenated amorphous silicon samples, 100, 300, and $500 \mathrm{~nm}$ thick, were laser treated in order to investigate the changes to the structural, optical, and electrical properties as a function of amorphous silicon thickness with excimer laser crystallization. The resulting nanocrystalline thin films were characterized using Raman spectroscopy, optical absorption measurements, atomic force microscopy, forward recoil spectrometry, and current-voltage measurements. The relationship of crystalline volume and laser energy density was established, along with the behavior of the optical gap and its relationship to hydrogen content. Surface roughness effects are discussed in the context of photovoltaic applications. The effect of increased mobility on photoconductivity after excimer laser crystallization is also examined. (C) 2005 American Institute of Physics. [DOI: 10.1063/1.1898444]
\end{abstract}

\section{INTRODUCTION}

Excimer laser (EL) crystallization has been the preferred method for polycrystalline thin-film formation for thin-film transistor (TFT) applications. ${ }^{1-3}$ The technology has evolved over the past 20 years, with an extensive array of literature. Most of the research has focused on improving the mobility of hydrogenated amorphous silicon $(a-\mathrm{Si}: \mathrm{H})$ by crystallization into polycrystalline silicon. Pulsed laser energy melts and solidifies thin $a$-Si:H films within nanosecond time scales, systematically evolving hydrogen and forming polycrystalline silicon. The short-wavelength, short pulse duration ultraviolet (UV) energy of the EL is absorbed into the $a$-Si:H within a few nanometers, with a minimum percentage of heat reaching the substrate. This enables the use of cheap substrates such as glass that cannot withstand conventional annealing temperatures for large area electronic applications. Although the application has primarily been focused on TFTs, its adaptability for photovoltaics (PV) has attracted considerable interest. ${ }^{4-7}$

The physics of EL crystallization has been well established. ${ }^{8-12}$ Two major streams of EL crystallization are reported, multiple pulse based and single pulse based. ${ }^{2}$ The multiple pulses based scanning method is considered to be the conventional approach. ${ }^{13}$ With the advent of high power excimer lasers, the single pulse scheme has become an attractive alternative, due to its ability to crystallize a large area with a single pulse. ${ }^{14}$

A laser threshold energy density exists for the conversion of $a$-Si:H to polycrystalline silicon, corresponding to the threshold intensity for surface melting. ${ }^{1}$ Films start to melt after this energy density, with the melt depth increasing with increase of energy density. Three basic transformation scenarios have been reported during the EL treatment. These are

\footnotetext{
a) Author to whom correspondence should be addressed; electronic mail: d.adikaari@surrey.ac.uk
}

categorized according to the melt depth as partial melting, complete melting, and near complete melting regimes. ${ }^{2}$ Partial melting occurs when the laser energy density is low, but sufficient to melt a layer of the film leaving a continuous solid layer underneath. This regime results in a stratified structure with large crystallites at the irradiating surface, followed by a fine-grained silicon layer. The underlying layer is expected to be amorphous, but its properties may be affected due to heat transfer. Although the resultant silicon is commonly known as polycrystalline silicon, the crystallites formed are in nanometer range and hence in this work, the term 'nano-polycrystalline' silicon is used to designate films crystallized by the partial melting regime. In the complete melting regime, the deeply supercooled melt increases nucleation rate causing a spontaneous nucleation process. The resulting films have a fine-grained crystalline structure. ${ }^{2,15}$

Between the two major regimes, another regime exists with very important characteristics. It was argued that, just before the complete melt, the unnmelted portion of the underlying silicon consists of islands of solids instead of a continuous layer. These unmelted solids separated by small local regions of completely melted silicon act as seed layers for lateral growth. ${ }^{2}$ This behavior at the critical point of complete melting has given the name 'near complete melting regime' to this scheme. The lateral growth results in very large grain sizes, a few times that of the film thickness. ${ }^{9}$ The ability of excimer lasers to crystallize a very thin layer of $a$-Si:H in the order of $100 \mathrm{~nm}^{1}$ becomes a limitation for photovoltaics, since films of the order of $1 \mu \mathrm{m}$ are necessary for adequate light absorption. ${ }^{16}$ Although films of 200-nmthick $a$-Si:H, with low hydrogen concentrations deposited by low-pressure chemical vapor deposition ${ }^{17}$ have been reported to be crystallized by EL, due to high absorption properties of $a$-Si:H at $\mathrm{UV}$, the attainable polysilicon thickness is inadequate for solar cell applications. The indirect band gap of crystalline silicon requires thicker films compared to $a$-Si:H. 


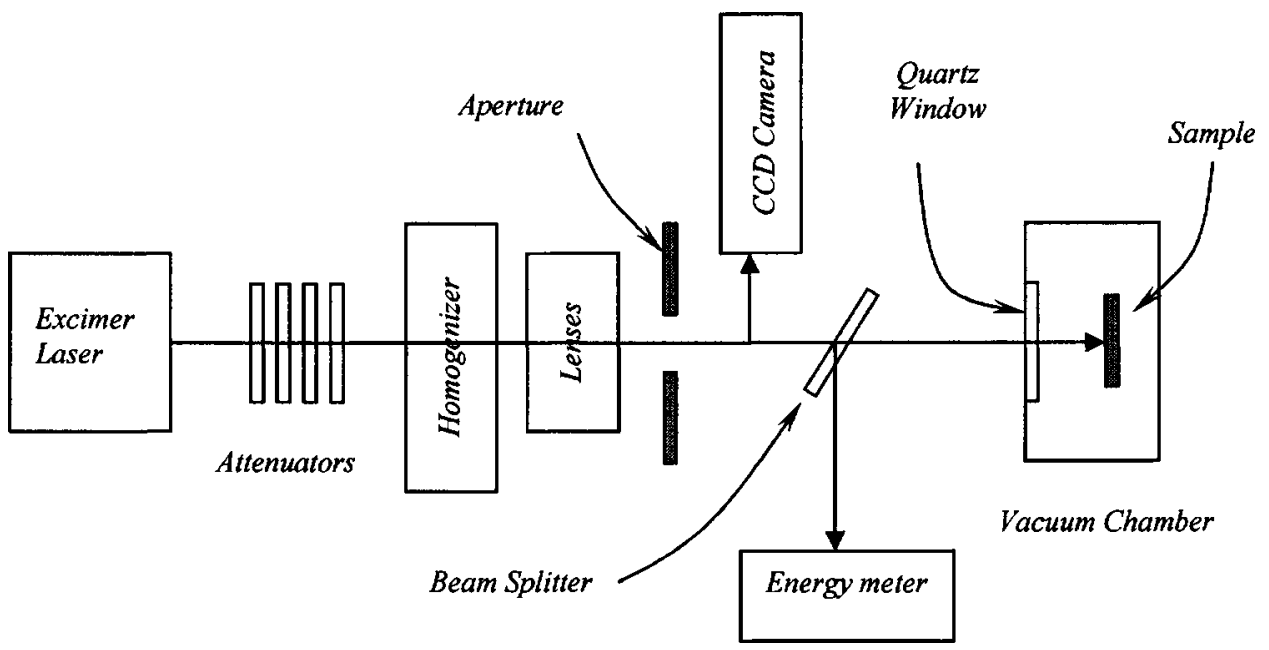

FIG. 1. Excimer laser crystallization experimental setup.

A systematic study of properties of films thicker than $100 \mathrm{~nm}$ upon excimer laser irradiation becomes important in this context. In this investigation, 100, 300, and $500 \mathrm{~nm}$ thick films were irradiated with a set of laser energy densities, and were characterized for structural and electrical properties. The experiment falls into the partial melting regime, resulting in layered structures. Raman spectroscopy was utilized to investigate the structural characteristics of samples. Optical absorption measurements were used for optical characterization and will be discussed along with the results obtained from hydrogen quantification. Atomic force microscopy (AFM) was used for surface analysis and the surface roughness effects will be discussed as a potential light trapping mechanism. Dark conductivities were calculated from current-voltage measurements. The discussion addresses thickness dependence of these parameters in the context of PV.

\section{EXPERIMENTAL DETAILS}

$a-\mathrm{Si}: \mathrm{H}$ films were deposited by plasma enhanced chemical vapor deposition (PECVD). $100 \mathrm{~nm}$ thick samples were deposited on $0.7 \mathrm{~mm}$ thick Corning 1737 glass covered with a PECVD grown $100 \mathrm{~nm}$ silicon nitride layer followed by a $400 \mathrm{~nm}$ silicon dioxide $\left(\mathrm{SiO}_{2}\right)$ layer. The 300 and $500 \mathrm{~nm}$ thick samples were deposited without the silicon dioxide layer. All samples were intrinsic (not intentionally doped) and deposited at $250{ }^{\circ} \mathrm{C}$. The samples will be referred to as 100, 300, and $500 \mathrm{~nm}$ samples in the text.

A KrF Lambda Physik excimer laser (LPX 210i) operating at $248 \mathrm{~nm}$ with a $25 \mathrm{~ns}$ full width half maximum pulse duration was used for irradiations. A set of attenuators is used as a secondary control of laser energy density, and a set of optics located outside the LPX 210i guides the beam to the irradiating chamber. The beam is homogenized using a Microlas beam homogenizer to obtain a semi-Gaussian profile and the profile is captured by an Exitech Profile 256 system, for the analysis of the energy distribution. The samples are placed in a vacuum chamber fixed on a micron precise translation stage for scanning the film in order to yield large area crystallization. The laser energy is measured using a Molectron EPM 1000 analyzer and a detector. The actual experimental setup is shown in Fig. 1. The scanning speed of the films was $2.5 \mathrm{~mm} / \mathrm{s}$ with a pulse repetition rate of $50 \mathrm{~Hz}$. The films were scanned with a $4 \mathrm{~mm}$ wide pulse along the $10 \mathrm{~mm}$ long Gaussian direction with an overlap of $5 \%$ between two scan lines. This arrangement results in a 'multiple pulse irradiation' scheme with a pulse density of 200 at a given spot. A series of laser energy densities was used for the crystallization from 50 to $300 \mathrm{~mJ} \mathrm{~cm}^{-2}$, in steps of $50 \mathrm{~mJ} \mathrm{~cm}^{-2} .300 \mathrm{~mJ} \mathrm{~cm}^{-2}$ was the maximum energy density uniformly attainable, due to constraints associated with the experimental setup. The laser energy densities are quoted for a single pulse. The pulse-to-pulse variation of modern excimer lasers is reported to be $6 \%-9 \%$, hence the laser energy densities are expected to have an error of at least $10 \% .^{18}$

Optical transmission measurements of the samples were done with a Camspec M330 UV-visible spectrophotometer and Raman spectroscopy with a Renishaw 2000 Raman microscope with a 782-nm excitation. Elastic forward recoil spectrometry (FRS) was performed using a 2-MV Tandetron accelerator and customized IBA Data Furnace software for the quantification of hydrogen in the resulting films. Surface roughnesses of the samples were estimated using atomic force microscopy. A Digital Instruments, Dimension 3100 scanning probe microscope was used in AFM mode for measurements. Room-temperature, current-voltage measurements of the samples were done using a coplanar electrode configuration with a Keithley 487 picoammeter/voltage source.

\section{RESULTS AND DISCUSSION}

\section{A. Raman spectroscopy}

It has been observed that the resulting microstructure of EL-treated $a-\mathrm{Si}: \mathrm{H}$ gives rise to partial melting and thereby results in a stratified structure. ${ }^{2}$ The stratified microstructure of EL crystallized silicon thin films makes it difficult to estimate the investigation depth of samples from Raman microscopy. However, with the film depths under discussion, which are less than a micron, Raman spectra are expected to contain information for the complete layer.

The Raman spectrum of mixed phase silicon has two distinct peaks corresponding to an amorphous phase and crystalline phase. For crystalline silicon, momentum conser- 


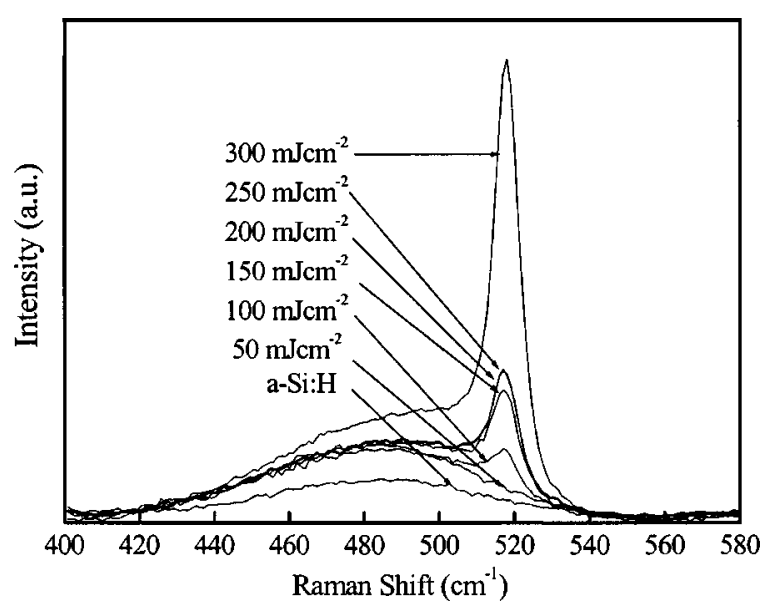

FIG. 2. Raman spectra of $500 \mathrm{~nm}$ samples.

vation rules result in a single sharp peak close to $520 \mathrm{~cm}^{-1}$, corresponding to the transverse-optical (TO) phonon mode. The TO peak is dominant for $a-\mathrm{Si}: \mathrm{H}$ as well, however, with a broader and low intensity peak around $475 \mathrm{~cm}^{-1}$. In mixed phase silicon, the momentum selection rule of the Raman process is more relaxed compared to crystalline silicon. With increasing momentum the TO phonon energy lowers, leading to broadening of the Raman peak towards the lower energies. ${ }^{19,20}$

Figure 2 shows the Raman spectra for $500 \mathrm{~nm}$ samples, crystallized with different laser energy densities. Evidence of a crystalline phase starts to show after an energy density of $100 \mathrm{~mJ} \mathrm{~cm}{ }^{-2}$. A clear trend of increasing crystallinity is observed as expected from the EL crystallization. The wide TO peak of $a-\mathrm{Si}: \mathrm{H}$ is evident in almost all the films investigated, with decreasing intensities. The crystalline peak becomes sharp after $250 \mathrm{~mJ} \mathrm{~cm}^{-2}$ for $500 \mathrm{~nm}$ films. However, the peak occurs at $518 \mathrm{~cm}^{-1}$, which is lower by a few wave numbers than the number observed for monocrystalline silicon. This observation has been attributed to phonon confinement, ${ }^{21}$ possibly due to the presence of nanocrystals embedded in $a$-Si:H environment. Stress-induced effects are also reported to cause this behavior. ${ }^{21}$

Similar trends are observed for 100 and $300 \mathrm{~nm}$ samples. The crystalline peak becomes increasingly prominent with thinner samples, due to melting and resolidification of the comparatively higher volume of film. The crystalline volume fractions of samples were calculated from the integrated intensities of the Raman peaks, with Gaussian fits for the amorphous peak $\left(I_{a}\right)$ and Lorentzian fits for the crystalline peaks $\left(I_{c}\right)$. The calculation was done as proposed by Tsu et al. with crystalline volume fraction $\left(X_{c}\right)$ given by Eq. (1), where $\gamma$ is the ratio of the backscattering cross-sections amorphous and crystalline phases, ${ }^{22}$

$$
X_{c}=\frac{I_{c}}{I_{c}+(\gamma) I_{a}} .
$$

The selection of a value for $\gamma$ is complex due to its dependency on absorption coefficient of amorphous and crystalline silicon. ${ }^{23}$ Different energy densities result in different grain sizes, which further complicates the analysis, since the absorption coefficient changes too. ${ }^{24} \gamma$ has been calculated to

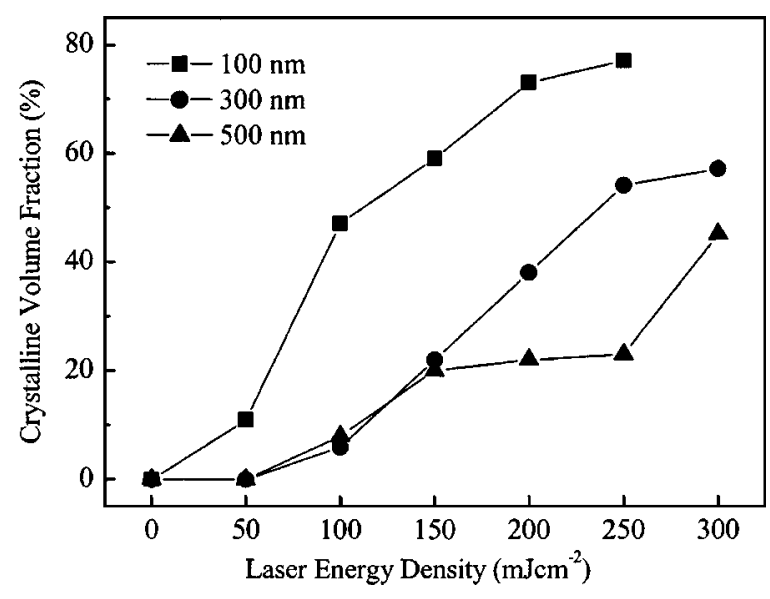

FIG. 3. Crystalline volume fractions of 100, 300, and $500 \mathrm{~nm}$ samples from Raman spectroscopy with excimer laser energy density.

be between 0.8 and 0.9 , the most widely used value being 0.8 for mixed phase silicon, especially for excimer laser crystallized silicon. ${ }^{23,25,26}$ For this analysis too, $\gamma$ was taken to be 0.8 . Figure 3 shows the $X_{c}$ variation of all three sets of films with laser energy density.

Room-temperature thermal conductivities of Corning 1737 glass $\left(0.91 \mathrm{Wm}^{-1} \mathrm{~K}^{-1}\right),{ }^{27} a$-Si:H $\left(1.0 \mathrm{Wm}^{-1} \mathrm{~K}^{-1}\right){ }^{28}$ and $\mathrm{SiO}_{2}\left(1.0 \mathrm{Wm}^{-1} \mathrm{~K}^{-1}\right)^{29}$ grown by PECVD are comparable to silicon nitride $\left(0.8 \mathrm{Wm}^{-1} \mathrm{~K}^{-1}\right)^{29}$ grown by PECVD, based on the film thickness and varies with temperature and follows a similar trend. Hence, it is proposed that solidification velocities of the samples under discussion are similar, provided that the at. $\%$ of hydrogen in the films are the same. A clear trend of increasing crystalline volume with increase of laser energy density is observed. The $100 \mathrm{~nm}$ film shows the highest $X_{c}$, at $250 \mathrm{~mJ} \mathrm{~cm}{ }^{-2}$. The highest energy density, $300 \mathrm{~mJ} \mathrm{~cm}^{-2}$, was not used on this sample since significant mass transfer was evident at $250 \mathrm{~mJ} \mathrm{~cm}^{-2}$. The 300 and 500 $\mathrm{nm}$ samples also show the increasing trend, however, with lower $X_{c}$, due to the inadequacy of the laser energy to completely melt the films through the entire thickness. This technique yields a rough estimate of $X_{c}$, and the Raman spectra itself is evident for the nanocrystallites embedded in the film. However, accurate information with regard to grain size and its distribution cannot be extracted from Raman spectroscopy alone, due to the stratified nature of the films.

The amorphous fraction in the resultant films is postulated as arising from any remaining unconverted $a-\mathrm{Si}: \mathrm{H}$ and grain boundaries. From these observations, it can be stated that to crystallize films thicker than $300 \mathrm{~nm}$, very high en-

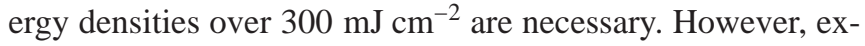
periments show that higher energy densities result in increased surface roughness, possibly due to explosive evaporation of hydrogen, ablating the surface. Use of longer wavelength ELs, which will have a longer absorption depth into the films, will be a possible solution to overcome this problem. $^{30}$

The utilization of 'large-grained/fine-grained/amorph ous' layered silicon structure from EL crystallization as the absorber layer, instead of conventional homogeneous $a-\mathrm{Si}: \mathrm{H}$ 


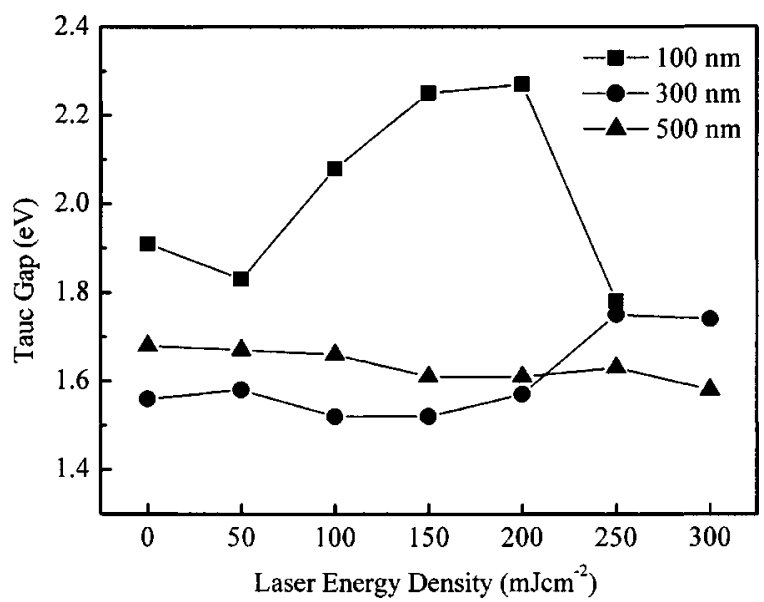

FIG. 4. Optical gap of 100,300 , and $500 \mathrm{~nm}$ samples calculated using Tauc's method.

or nanocrystalline silicon absorber layers, promises great potential for photovoltaics, provided that the associated carrier collection complexities are addressed.

\section{B. Optical absorption}

Optical absorption of the samples was used to estimate the optical gap using Tauc's method. Measurements were performed at a near normal incidence from 190 to $900 \mathrm{~nm}$ wavelength range. For the extraction of the optical gap, several models have been proposed for amorphous semiconductors. However, Tauc's method has been the most preferred technique, compared to the models of Cody and Klazes. ${ }^{31}$ According to Tauc, if the band edges are parabolic, with constant momentum matrix elements, the optical gap can be found by the relationship given in Eq. (2),

$$
\sqrt{\alpha h v}=A_{t}\left(h v-E_{g}\right) \text {. }
$$

Due to the layered structures of the substrates, the effect of reflections on the optical transmission spectra has a significant influence on calculations. The multiple internal reflections were disregarded for this analysis, with the assumption that the effect is small near the medium absorption region. The data was corrected for reflections using a simplified model as suggested by Nitta et $_{\text {al. }}{ }^{32}$

Figure 4 shows the extracted optical gaps of all three sets of films from Tauc's method. A direct correlation cannot be clearly seen between the three sets of samples. Theoretical analysis on mixed phase silicon suggests a gradual decrease of the Tauc gap with increasing $X_{c} \cdot{ }^{33}$ A contradictory observation is made in the case of $100 \mathrm{~nm}$ samples, where the optical gap seems to increase considerably between 150 and $200 \mathrm{~mJ} \mathrm{~cm}^{-2}$. The same phenomenon can be seen with 300-nm samples, although less significantly. $500 \mathrm{~nm}$ samples only show a very slow gradual reduction of Tauc gap. This phenomenon is proposed to be mainly due to critical compositions of hydrogen in the films, which enhances the recession of valence band of $a$-Si:H/nanocrystalline silicon. Von Roedern et al. showed that this recession can be as high as 1 $\mathrm{eV}$ for amorphous silicon. ${ }^{34}$ The variation of the optical gap of $a$-Si:H depending on $\mathrm{H}$ content shows similar characteristics. ${ }^{28}$ Also, quantum confinement effects due to

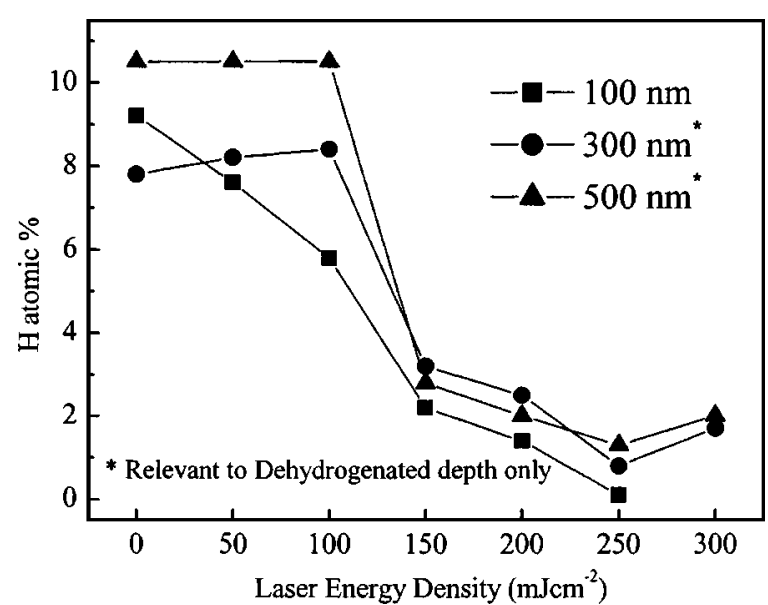

FIG. 5. Hydrogen atomic percentage of 100, 300, and $500 \mathrm{~nm}$ samples analyzed by FRS. For 300 and $500 \mathrm{~nm}$ thick samples, the $\mathrm{H}$ percentage shown is relevant only to dehydrogenated layer, which is shown in Fig. 6.

the fine-grained nanocrystalline silicon layer could enhance this phenomenon. The effect is reported in detail elsewhere. ${ }^{35}$ The effect is less evident in the $300 \mathrm{~nm}$ samples, and not relevant to the $500 \mathrm{~nm}$ samples with the discussed energy densities, due to the inadequacy of laser energy to melt films up to the critical depth, which in turn affects retained hydrogen in the films. It is suggested that results similar to those observed for $100 \mathrm{~nm}$ films can be obtained for thicker films, using excimer laser energy densities greater than $300 \mathrm{~mJ} \mathrm{~cm}^{-2}$. However, it is also speculated that, due to the higher volumes of material involved in this case, the effect may not be as prominent as the $100 \mathrm{~nm}$ samples. Since the films are not completely converted to crystalline silicon, the estimated Tauc gap is influenced by the different optical properties of each layer of resulting silicon. For PV applications, this could be a useful property, since the resulting material can absorb a range of photon energies. However, the complexities involved in transport and collection of excited carriers will have to be dealt with for possible exploitation of these characteristics.

\section{Dehydrogenation}

Dehydrogenation occurs as a result of EL crystallization since the $\mathrm{Si}-\mathrm{H}(3.4 \mathrm{eV})^{28}$ bonds are broken by the energy absorbed from the EL photon $(5.1 \mathrm{eV})$. Released hydrogen evaporates from the silicon melt, causing surface roughness. ${ }^{36}$ Different techniques have been utilized for controlled evolution of hydrogen. Gaussian beam profiles used for these experiments are reported to be an efficient means of systematic evolution of hydrogen, due to the lower-energy preceding edge. ${ }^{37}$ Figure 5 shows the atomic percentages of hydrogen $(\mathrm{H}$ at. \%) in the samples as a function of laser energy density obtained using FRS.

$\mathrm{H}$ at. $\%$ of initial $a-\mathrm{Si}: \mathrm{H}$ was $9.5,8.5$, and 10.5 , respectively, for 100,300 , and $500 \mathrm{~nm}$ samples. The small variation of initial hydrogen is expected due to different deposition runs. The $100 \mathrm{~nm}$ samples show an almost linear dehydrogenation pattern, removing almost all the hydrogen from the sample at $250 \mathrm{~mJ} \mathrm{~cm}{ }^{-2}$. The FRS results for 300 and $500 \mathrm{~nm}$ samples suggest at a glance that hydrogen evolution starts 


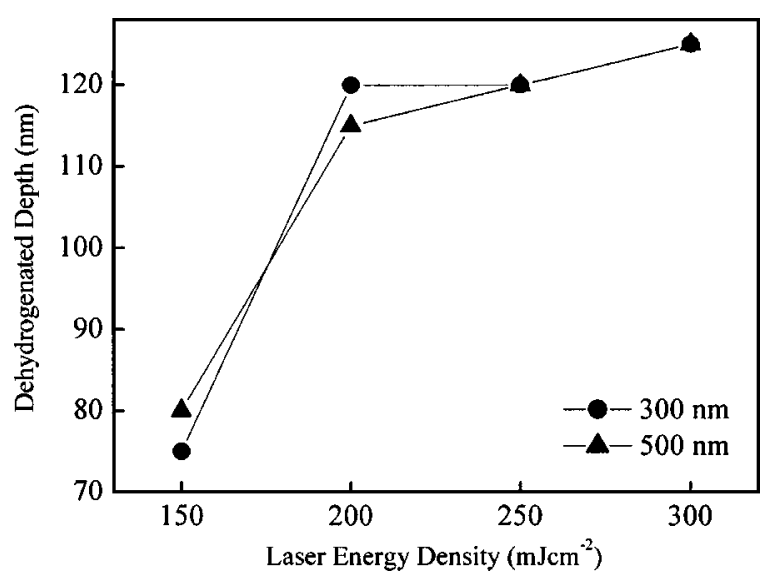

FIG. 6. Dehydrogenated depth of 300 and $500 \mathrm{~nm}$ samples against laser energy density.

after $100 \mathrm{~mJ} \mathrm{~cm}{ }^{-2}$ and dehydrogenates the films to a value of $2 \%$ at $300 \mathrm{~mJ} \mathrm{~cm}^{-2}$. However, a careful investigation of the FRS analysis shows two distinct layers of film with different hydrogen contents after irradiation above $100 \mathrm{~mJ} \mathrm{~cm}^{-2}$. The trend shown in Fig. 5 corresponds to the top layer, whereas the $\mathrm{H}$ at. $\%$ of the second layer does not change. The depth of the top layer increases with laser energy density, as shown in Fig. 6. These dehydrogenated depths are similar for both 300 and $500 \mathrm{~nm}$ films, confirming that the crystallization environment and mechanism are similar for both sets of films and therefore thickness independent to an extent.

Since hydrogen has a significant influence on the electronic properties of $a-\mathrm{Si}: \mathrm{H}$, these stratified structures from the EL crystallization have complex electronic properties, where they are governed by different mechanisms. If the effects of heat reaching the unconverted $a$-Si:H are disregarded, which has not been confirmed, electronic properties of this layer is most likely to be similar to the initial $a-\mathrm{Si}: \mathrm{H}$. However, the large-grained layer at the surface has a very high $X_{c}$ and its properties will be governed by the ordered crystal structure, apart from the contribution of the grain boundaries. The sandwiched, fine-grained nanocrystalline layer has the most complicated structure, with a considerable amount of crystallites and a similar amount of grain boundaries, which will act more as $a-\mathrm{Si}: \mathrm{H}$, and this is the true nanocrystalline layer from the partial melting regime.

\section{Surface roughness}

Significant levels of surface roughness have been a characteristic of EL crystallization of $a-\mathrm{Si}: \mathrm{H}$. Several parameters have been identified which influence the surface morphology of EL crystallized silicon. These include hydrogen evolution from $a$-Si:H, multiple shot crystallization, ${ }^{36}$ differences in latent heat and thermal conductivity between crystalline and amorphous silicon, ${ }^{38}$ capillary waves exited by volume change at the silicon melt transition from liquid to solid, ${ }^{39}$ and ambient condition of the irradiation atmosphere. ${ }^{36}$

The use of a semi-Gaussian beam shape reduces the roughness due to hydrogen evolution and keeping the irradiating atmosphere in vacuum helps reduce mass transfer from surface further. Surface roughnesses of the films were esti-

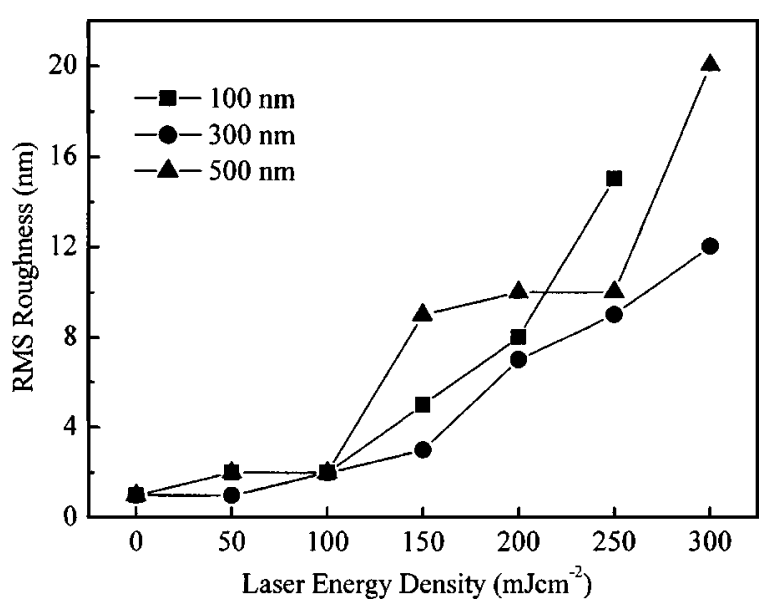

FIG. 7. Root-mean-square (rms) roughness of 100, 300, and $500 \mathrm{~nm}$ samples measured by AFM.

mated by AFM over a $25 \mu \mathrm{m}^{2}$ area. Figure 7 shows the surface roughness variation with laser energy density. An increasing trend of surface roughness is evident from the measurements for all three thicknesses, with a slight variation in the $500 \mathrm{~nm}$ films. The sudden increase of roughness for the $500 \mathrm{~nm}$ films starts at $150 \mathrm{~mJ} \mathrm{~cm}^{-2}$ and is attributed to $25 \%$ higher initial hydrogen percentage in the films (Fig. 5) compared to $300 \mathrm{~nm}$ thick films. Explosive evaporation of this abundant hydrogen is expected to be the principal reason for surface roughness to occur. ${ }^{36}$ From Fig. 6, it can be seen that for $500 \mathrm{~nm}$ samples, hydrogen starts to evolve from the top layer at $150 \mathrm{~mJ} \mathrm{~cm}{ }^{-2}$. Therefore, it is proposed that even with the optimum laser beam shape for hydrogen evolution, $^{40}$ hydrogen evolution dominates the surface roughness of EL crystallized silicon.

Surface roughness becomes a significant issue for TFT applications, due to uniformity related problems. However, this phenomenon does show an interesting potential for solar cell applications. ${ }^{41}$ Figure 8 shows a three-dimensional (3D) view of the surface micrograph of $500 \mathrm{~nm}$ sample crystallized at $250 \mathrm{~mJ} \mathrm{~cm}^{-2}$. The cross-sectional view shows the nature of the surface at this energy, which is highly desirable for light trapping in photovoltaic applications. This quality of EL crystallized silicon can be very advantageous if the process is tailored for solar cell applications, yielding a surface texturing process without additional cost.

\section{E. Dark conductivity}

Room-temperature dark conductivities of the samples were calculated from current-voltage measurements. The electrode configuration was coplanar, with a $3 \mathrm{~mm}$ effective length and a $10 \mu \mathrm{m}$ separation. Figure 9 shows the variation of dark conductivity with laser treatment. The conductivities of initial $a-\mathrm{Si}: \mathrm{H}$ are of the order of $1 \times 10^{-10} \mathrm{~S} / \mathrm{cm}$ for 100 and $300 \mathrm{~nm}$ samples, whereas for the $500 \mathrm{~nm}$ samples it is an order of magnitude higher. The dark conductivities of $a-\mathrm{Si}: \mathrm{H}$ prepared by PECVD are highly sensitive to process parameters. ${ }^{28}$ It is proposed that $500 \mathrm{~nm}$ initial $a$-Si:H films are better quality material due to adequate hydrogen passivation of dangling bonds, with its relatively higher hydrogen at. \%. Dark conductivities increase rapidly with EL crystal- 



FIG. 8. (a) Three-dimensional AFM image of $500 \mathrm{~nm}$ sample crystallized at $250 \mathrm{~mJ} \mathrm{~cm}^{-2}$ with horizontal scale one micron per division and vertical scale $50 \mathrm{~nm}$ per division (b) its cross-sectional view. lization for all three sets of samples, with the values increasing with a similar trend as laser energy density is increased. The $500 \mathrm{~nm}$ samples show a lower increase compared to 100 and $300 \mathrm{~nm}$ samples. This is proposed to be due to the amorphous phase dominating from the thick unmelted layer underneath, compared to $100 \mathrm{~nm}$ films. Although dark conductivities increase and start to show trends of saturation, similar work previously reported shows an increase of conductivities up to $1 \mathrm{~S} / \mathrm{cm}^{42}$ Higher conductivity from EL crystallized silicon has been the most desirable feature for TFT applications, with the higher conductivities caused by increased mobilities of the material. ${ }^{1}$ The increase in mobilty is accepted to be due to the grain boundaries in polycrystalline silicon,

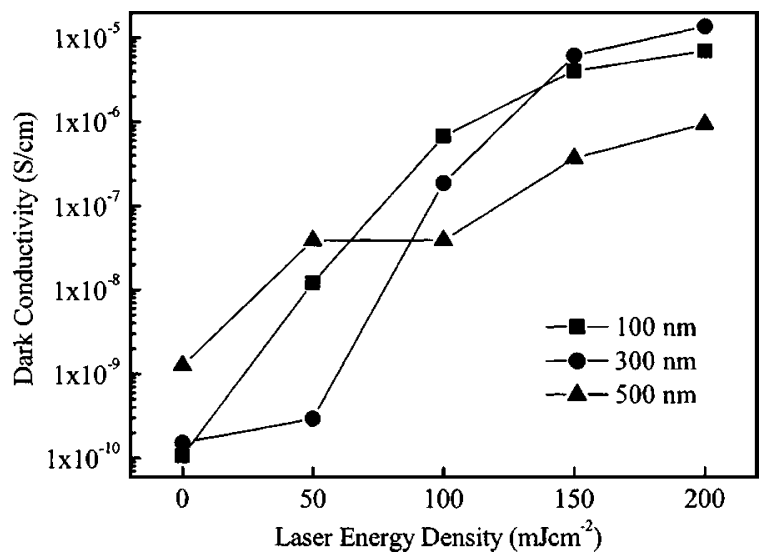

FIG. 9. Dark conductivities of 100, 300, $500 \mathrm{~nm}$ samples with laser energy density. although it has not been dealt with by taking into account the stratified nature of EL crystallized silicon. Conductivity can also be enhanced by addition/activation of impurities during EL crystallization. It is proposed that this is not significant for the films under discussion as they were not intentionally doped and bulk impurity addition is insignificant at the base pressure used for crystallization.

It is stated that dark conductivity should be less than 1 $\times 10^{-10} \mathrm{~S} / \mathrm{cm}$ and photoconductivity should be greater than $1 \times 10^{-5} \mathrm{~S} / \mathrm{cm}$ (Ref. 43) for device quality amorphous and microcrystalline silicon, in the context of PV. In order to utilize the desirable properties of EL crystallized silicon, their dark conductivities need to be reduced. Grain-boundary passivation using hydrogen has been reported as an effective means of reducing the density of states in the gap, ${ }^{44}$ which may be one method of addressing this problem. The increased mobilities can effectively be used to realize desirable junction properties as well. Doped $a-\mathrm{Si}: \mathrm{H}$ is reported to yield very high conductivities, ${ }^{42}$ which can be used to make good ohmic contacts.

\section{CONCLUSIONS}

The thickness dependence of structural, optical, and electrical properties of EL crystallized silicon was investigated. The level of crystalline fraction $\left(X_{c}\right)$ was determined, and it is concluded that it is not possible to convert $a-\mathrm{Si}: \mathrm{H}$ films thicker than $300 \mathrm{~nm}$ completely to polycrystalline silicon at this wavelength, without utilizing laser energy densities in excess of $300 \mathrm{~mJ} \mathrm{~cm}^{-2}$. Stratification of 300 and 500 
nm films under a partial melting regime was confirmed from FRS analysis as well. The presence of different levels of hydrogen in different sized crystallite layers is suggested to result in different optical and electronic properties in each layer. Hence, this structure is identified as a potential multiphoton absorber, provided the complexities in transport and collection are resolved. The surface roughness due to EL crystallization is proposed as a 'no cost' surface texturing mechanism in the event of PV applications. Dark conductivity of the films increases after EL crystallization, and grainboundary passivation with hydrogen is suggested to be a potential remedy for improvements, which needs further investigation.

\section{ACKNOWLEDGMENTS}

The authors would like to thank Phillips Research Laboratories, Redhill, Surrey, UK, for the supply of $a-\mathrm{Si}: \mathrm{H}$ samples, G.Y. Chen for Raman measurements and C. E. Giusca for AFM analysis. This work is supported by the Portfolio Partnership Award from EPSRC.

${ }^{1}$ S. D. Brotherton, Semicond. Sci. Technol. 10, 721 (1995); S. D. Brotherton, D. J. McCulloch, J. B. Clegg, and J. P. Gowers, IEEE Trans. Electron Devices 40, 407 (1993); S. D. Brotherton, D. J. McCulloch, J. P. Gowers, J. R. Ayres, and M. J. Trainor, J. Appl. Phys. 82, 4086 (1997).

${ }^{2}$ J. S. Im, H. J. Kim, and M. O. Thompson, Appl. Phys. Lett. 63, 1969 (1993), J. S. Im et al., Phys. Status Solidi A 166, 603 (1998).

${ }^{3}$ T. Sameshima and S. Usui, Appl. Phys. Lett. 59, 2724 (1991).

${ }^{4}$ H. Azuma, A. Takeuchi, T. Ito, H. Fukushima, T. Motohiro, and M. Yamaguchi, Sol. Energy Mater. Sol. Cells 74, 289 (2002).

${ }^{5}$ K. Yamamoto, A. Nakashima, T. Suzuki, M. Yoshimi, H. Nishio, and M. Izumina, Jpn. J. Appl. Phys., Part 2 33, L1751 (1994).

${ }^{6}$ W. -C. Yeh and M. Matsumura, Jpn. J. Appl. Phys., Part 2 38, L110 (1999).

${ }^{7}$ P. Lengsfeld, S. Christiansen, M. Nerding, M. Rebien, W. Henrion, I. Sieber, and N. H. Nickel, Solid State Phenom. 80-81, 181 (2001).

${ }^{8}$ M. O. Thompson, G. J. Galvin, J. W. Mayer, P. S. Peercy, J. M. Poate, D. C. Jacobson, A. G. Cullis, and N. G. Chew, Phys. Rev. Lett. 52, 2360 (1984).

${ }^{9}$ J. S. Im and H. J. Kim, Appl. Phys. Lett. 64, 2303 (1994); H. J. Kim and J. S. Im, ibid. 68, 1513 (1996); R. S. Sposili and J. S. Im, ibid. 69, 2864 (1996); J. S. Im, R. S. Sposili, and M. A. Crowder; ibid. 70, 3434 (1997).

${ }^{10}$ P. Mei, J. B. Boyce, M. Hack, R. A. Lujan, R. I. Johnson, G. B. Anderson, D. K. Fork, and S. E. Ready, Appl. Phys. Lett. 64, 1132 (1994).

${ }^{11}$ G. Ivlev, E. Gatskevich, V. Chab, J. Stuchlik, V. Vorlicek, and J. Kocka, Appl. Phys. Lett. 75, 498 (1999).

${ }^{12}$ G. Williams, D. Sands, R. M. Geatches, and K. J Reeson, Appl. Phys. Lett. 69, 1623 (1996).

${ }^{13}$ J. S. Im and R. S. Sposili, Mater. Res. Bull. 21, 39 (1996)

${ }^{14}$ Y. Helen et al., Thin Solid Films 337, 133 (1999).

${ }^{15}$ M. Hatano, S. Moon, M. Lee, K. Suzuki, and C. P. Grigoropoulos, J. Appl.
Phys. 87, 36 (2000)

${ }^{16}$ H. Keppner, J. Meier, P. Torres, D. Fischer, and A. Shah, Appl. Phys. A: Mater. Sci. Process. 69, 169 (1999).

${ }^{17}$ F. C. Voogt, R. Ishihara, and F. D. Tichelaar, J. Appl. Phys. 95, 2873 (2004).

${ }^{18}$ A. T. Voustas, Appl. Surf. Sci. 208-209, 250 (2003).

${ }^{19}$ A. T. Voutsas, M. K. Hatalis, J. Boyce, and A. Chiang, J. Appl. Phys. 78, 6999 (1995).

${ }^{20}$ C. Smit, R. A. C. M. M. van Swaaij, H. Donker, A. M. H. N. Petit, W. M. M. Kessels, and M. C. M. van de Sanden, J. Appl. Phys. 94, 3582 (2003).

${ }^{21}$ E. Fogarassy, H. Pattyn, M. Elliq, A. Slaoui, B. Prevot, R. Stuck, S. de Unamuno, and E. L. Mathé, Appl. Surf. Sci. 69, 231 (1993).

${ }^{22}$ R. Tsu, J. Gonzalez-Hernandez, S. S. Chao, S. C. Lee, and K. Tanaka, Appl. Phys. Lett. 40, 534 (1982).

${ }^{23}$ E. Bustarret, M. A. Hachicha, and M. Brunel, Appl. Phys. Lett. 52, 1675 (1988).

${ }^{24}$ H. Kakinuma, M. Mohri, M. Sakamoto, and T. Tsuruoka, J. Appl. Phys. 70, 7374 (1991).

${ }^{25}$ A. T. Voutsas, M. K. Hatalis, J. Boyce, and A. Chiang, J. Appl. Phys. 78, 6999 (1995)

${ }^{26}$ P. Lengsfeld, N. H. Nickel, and W. Fuhs, Appl. Phys. Lett. 76, 1680 (2000).

${ }^{27}$ http://www.corning.com/displaytechnologies/en/products_services/1737f/

${ }^{28}$ Properties of Amorphous Silicon and its Alloys, edited by Tim Searle (INSPEC, London, 1998).

${ }^{29}$ S. - M. Lee and David G. Cahill, J. Appl. Phys. 81, 2590(1997).

${ }^{30}$ Y. F. Tang, S. R. P. Silva, and M. J. Rose, Appl. Phys. Lett. 78, 186 (2001).

${ }^{31}$ R. Swanepoel, in Properties of Amorphous Silicon and its Alloys, edited by Tim Searle, (INSPEC, London, 1998).

${ }^{32}$ S. Nitta, S. Itoh, M. Tanaka, T. Endo, and A. Hatano, Sol. Energy Mater. Sol. Cells, 8, 249 (1982).

${ }^{33}$ C. Rotaru, S. Nastase, and N. Tomozieu, Phys. Status Solidi A 171, 365 (1999).

${ }^{34}$ B. von Roedern, L. Ley, M. Cardona, and F. W. Smith, Philos. Mag. B 40, 433 (1979).

${ }^{35}$ A. A. D. T. Adikaari and S. R. P. Silva, Appl. Phys. Lett. (to be published).

${ }^{36}$ D. J. McCulloch and S. D. Brotherton, Appl. Phys. Lett. 66, 2060 (1995).

${ }^{37}$ S. D. Brotherton, D. J. McCulloch, and M. J. Edwards, Solid State Phenom. 37-38, 299 (1994)

${ }^{38}$ I. Asai, N. Kato, M. Fuse and T. Hamano, Jpn. J. Appl. Phys., Part 1: Regular Papers, Short Notes and Review Papers 32, 474 (1993).

${ }^{39}$ D. K. Fork, G. B. Anderson, J. B. Boyce, R. I. Johnson, and P. Mei, Appl. Phys. Lett. 68, 2138 (1996).

${ }^{40}$ S. D. Brotherton, D. J. McCulloch, and M. J. Edwards, Solid State Phenom. 37-38, 299 (1994).

${ }^{41}$ D. Redfield, 11th IEEE Photovoltaic Specialists Conference, Scottsdale, Ariz., May 6-8, 1975, Conference Record (A76-14727 04-44), New York, Institute of Electrical and Electronics Engineers, Inc., 1975, pp. 431-432.

${ }^{42}$ K. Winer, G. B. Anderson, S. E. Ready, R. Z. Bachrach, R. I. Johnson, F. A. Ponce, and J. B. Boyce, Appl. Phys. Lett. 57, 2222 (1990).

${ }^{43}$ R. E. I. Schropp and M. Zeman, Amoprhous and Microcrystalline Silicon Solar Cells: Modelling, Materials and Device Technology (Kluwer Academic Publishers, London, 1998).

${ }^{44}$ N. H. Nickel, G. B. Anderson, and R. I. Johnson, Phys. Rev. B 56, 12065 (1997). 